\title{
Knowledge Management, Semantic Web and Logic of Significances to Create Technologic Skills for Support e-Learning Methodologies
}

\author{
Patricia Carrillo Velázquez
}

\begin{abstract}
E-learning prove useful in the interaction between student and teacher regardless of geographical distance, bringing the scope of education to a new dimension and improving the development of nations. However, in developing countries teachers requires strong skill building in science and technology in order to ensure the operation and efficiency of specific e-learning methodologies. In the case of Mexico, researchers are responsible of teaching activities in higher education. This requires breaking disciplinary schemes, functional structure and generation gaps when it comes to train researchers from the social sciences. That is caused by difficulties to understand the technological function and operation. We understand KM (Knowledge Management) as a strategic process to promote, create and transform the competitive capabilities in all kind of organization through diverse knowledge representations. This is closely linked with the ICT (Information and Communications Technology) because it makes possible to operate KM. We explain the construction process of multidisciplinary links as a Logic of significances based in the Constructivist theory and the web semantic as an instrument for knowledge representation useful to development and analyze these process. From this perspective we propose a methodology to create multidisciplinary links in a researching-teaching group of social and technology to transforms its technological skills and competitive capabilities to use, design and develop e-learning software and methodology. The preliminary result shows the social analysis categories as knowledge representation of the logic of significances of a researching-teaching group who design an e-learning software and the same time a social research instrument.
\end{abstract}

Index Terms-Telematic technology, semantic web, logic of significances, multidisciplinary and interdisciplinary research, representation of knowledge, science and technology.

\section{E-LEARNING AND KNOWLEDGE MANAGEMENT}

Knowledge Management (KM) as a strategic perspective aimed at promoting the creation and transformation of knowledge to create competitive organizational capacities [1]-[4].

Since 2002, we noted that various academic organizations in Mexico, have widely adopted KM to characterize and describe activities for the construction and transformation of various types of knowledge. Especially in e-learning activities in which is evident its operation with Information and Computing Technologies (ICT). The theoretical conception of the KM explains processes of the knowledge

Manuscript received June 10, 2013; revised August 14, 2013.

Patricia Carrillo Velázquez is with the Universidad Nacional Autónoma de México, CEIICH, Distrito Federal, México (e-mail: carrillopatricia4@gmail.com). construction in organizational contexts and their operational implementation is based in representations of knowledge with ICT [5].

This situation shows us one of "the areas of contemporary society that science and technology have transformed" [6], specifically the educational context.

Some of the challenges caused by the phenomena of social transformation that science and technology must take to ensure sustainable development are achieving the satisfaction of basic requirements, as education, and rising aspirations of the habitants of a region and ensure the availability of jobs facing technological changes, among others.

Nevertheless Latin America and Caribbean are considered the most inequitable regions in the world, and for this reason it is requires a strong scientific and technological development and skills to help counteract social inequality. The report of this region shows the lowest levels of attention to science and technology. The few that exist is focused on minorities of the population. In general, we consider to explain, discuss and find solutions to the context described, is required a solid education in science and technology to promote the participation of citizens in the democratic affairs of their nation and achieve a common good, worthy of a country fair [6].

Particularly the developing of knowledge is required for the use, appropriation, research and technological development to ensure the operation and efficiency of specific e-learning methodologies.

In the case of Mexico, researchers are responsible of teaching activities in higher education. This requires breaking disciplinary schemes, functional structure and generation gaps if comes to train researchers from the social sciences. That is caused by difficulties to understand the technological function and operation.

Hence we need to observe the interrelationships in the social system seen as a complex system to promote the interdisciplinary ${ }^{1}$ work and furthermore generate knowledge in perspective of the action around this social phenomenon. However, "at this moment and at the national level, the country-México- has lost a mayor part of talent to compete in the international arena" [6], and the higher Education sector is characterized by a disciplinary orientation.

For these reasons is priority to promote the development of technological capabilities in researchers-teachers, in order to influence the transformation of the current situation in Mexico, considering this group as responsible of create news knowledge and training students and new scientific professionals.

Although is possible that to transform the competitive capacity "take longer for professionals in humanities and 
social sciences, especially when the technology is not easy to use and understand" [7]. On the other hand, conceptual models and technological paradigms have been proposed to reformulate concepts and methodology process that can to influence for the understanding of the process of technological use and appropriation. That will support the technological skills and capabilities of researcher-teacher.

That is the case of the semantic web which based on the ontological representation of knowledge [8].

We understand that the semantic web is underpinned by inference reasoning based on the construction of a Logic of significances that begins with an exhaustive and rigorous semantic analysis of the fundamental concepts and classification criteria during formal research [9].

However, in the sphere that concerns us, the incorporation of these models and paradigms to bring about problems and multi- and inter-disciplinary objects of study that require collaborative work between researchers in the social sciences with specialists in technology like computer engineering, information sciences and communications.

Therefore, this research describes the paradigm of semantic web and explains its link with the Logic of Significances Theory at the same time that it is transforming its technological capacity and competitive from the perspective of KM.

\section{SEMANTIC WEB}

The semantic web paradigm is a conceptual model which representation of knowledge domains is structured around a basic ontology. Significances are established and built the scheme in that the relative entities are determined, together with their corresponding relations, which are also assigned significance. This also results in specialized semantic schemes with formal information contents, significances and relations for domains with specific knowledge [9].

According to Devedzic [8], the design and development of ICT application based on the paradigm of the semantic web usually includes:

- Automated connection of yet semantically related with the representations of different knowledge in a network whose information can even be located in various bases.

- Construction of common, standardized languages to represent significances through websites, in order to be discovered and linked in underlying data networks to implement the selection and combination of knowledge, even from different sources.

- Design and development of a system with the web applications required for automation and intelligent reasoning about the knowledge and their significances, in other words, for the "automated understanding" of the process to be implemented and requested to be processed, while finding and systematizing the necessary information.

Semantic web paradigm has been consolidated in the technological sphere despite it is not usually used in the research social environment because the ontology representation in a web interface is not only a group of hypertext links and technical processes, so development need expertise from knowledge social domain [7].

The background describes the utility of the Semantic Web in knowledge construction processes from different disciplinary areas. Comparatively it shows the incipient level of development regarding the technological applications based on this paradigm to social study. Therefore software based on the semantic web for contexts of specific social knowledge is obviously needs

\section{Semantic Web ANd Logic OF Significances}

The genesis of concept formation is an instrument that enables to understand how knowledge evolves in a particular type of organism from which it is impossible to dissociate and in the face of which the problem of the origin and the role played by logical structures emerges [10].

The relations and logic structures that develop in a cognitive process underpin the assimilating external conceptions and therefore to understand like "the others." Thus, a Logic of significances delves further into the "comprehensive" significances of logical operations and the "significant" implications as opposed to the "material" implications, thereby concerning itself with the truth and significance of their relations [10].

Located within this framework and the context of formal research, knowledge is the result of a permanent and dynamic open process of restructuring concepts and relations. There are emphasized in the case of multidisciplinary and inter-disciplinary research in which conceptions and perspectives from other disciplines must be shared.

We can assume, then, that the evolution of this process can be explained as the transition of relations during the structuring of a logic of significances, through three non-linear stages: Intra-operatory, inter-operatory and trans-operatory. (Piaget)

- Intra-operatory: refer to isolated, internal links that are not structured or coordinated with each other. They are limited to comparisons and correspondences, sets and series.

- Inter-operatory: these are related to elementary operators of association, reciprocity, commutation, transition and reversal.

- Trans-operatory: establish logical or mathematical relations such as grouping, combination or proportion, resulting from permutations, combinations, set definition on the basis of subsets or the integration of components into a whole.

These stages, which are basic and fundamental in the construction of a logic of significances explain the importance of the structuring of concepts and relations in a building process of new knowledge. That is relevant for understand and explicate social complex topics in the actual context whose understanding require different disciplinary knowledge on the social sphere. It particularly evidences the paramount importance of the new technological research instruments that have broken with the disciplinary frontiers in contrast with the traditional research instruments [11].

Therefore, highlight the importance of interdisciplinary and multidisciplinary relationship, the first between different social sciences and the other between social sciences and technology, both in formal research which involve science and technology. This perspective exposes the relevant of constructing and developing software based on semantic web paradigm for specific knowledge disciplinary links, that is, for the specific ontology. 


\section{METHOLOGY}

To contribute to the digital literacy of researchers-teacher for the efficient use of tools and methodologies for
e-Learning we promote dialogue between researchers-teachers of social sciences and technology developers.

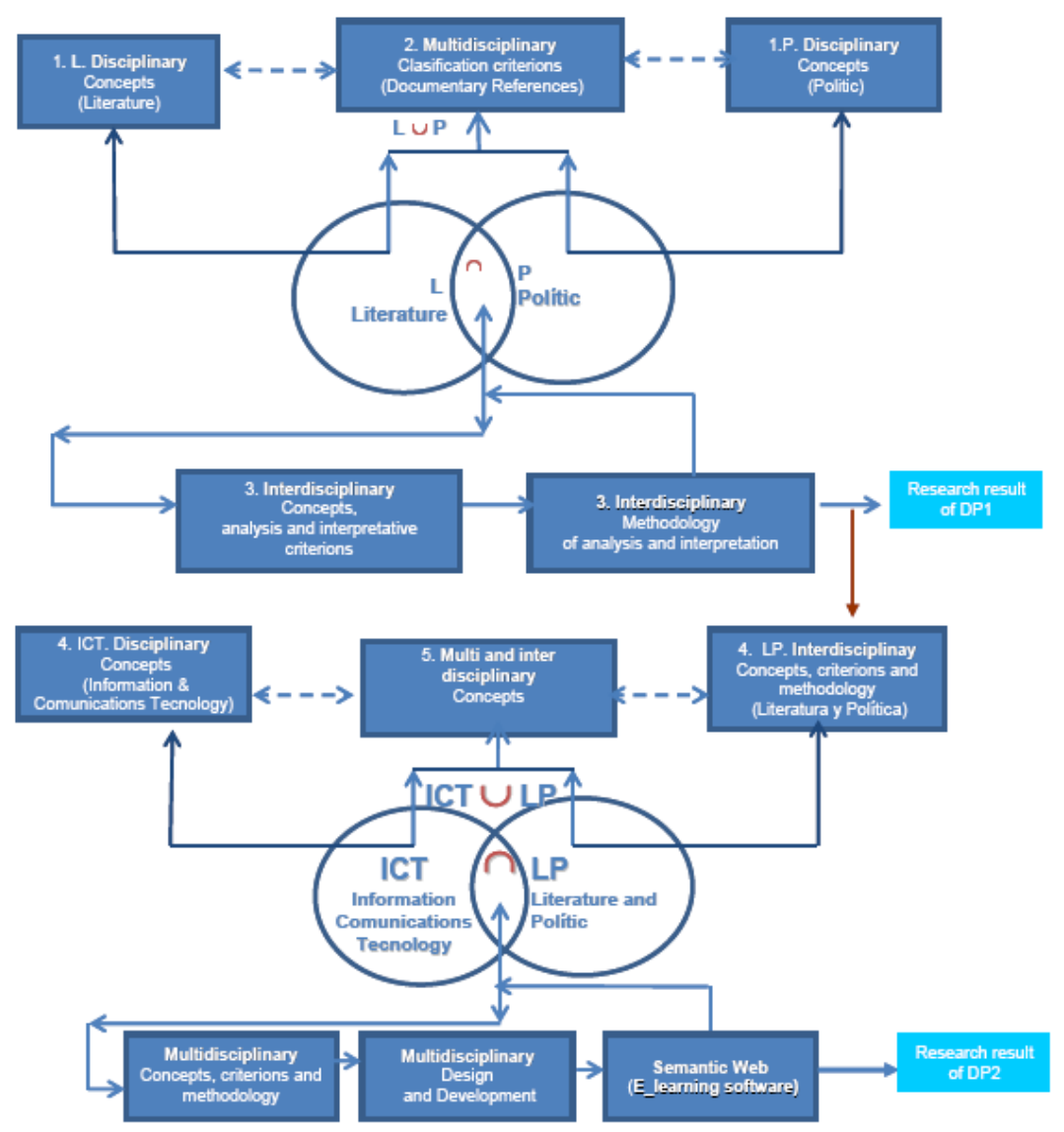

Fig. 1. Logic of significance.

With semantic web paradigm wedesign and development an ICT application. That is proprietary software regarding informational functional structure for the $\mathrm{KM}$ processes on social research group; we considerate them as an organization that need technology skills to operate and develop e-learning methodologies and tools.

From this paradigm, software design solves research and the same time encourages reasoning and knowledge technological construction on the action scheme of researcher It makes it possible to implement classificatory processes for the analysis and a broad variety of interpretative techniques for solving research problems. In this respect, the functional structure of software is based on semantic process of knowledge representation in order to implement and facilitate analysis, interpretation and understanding of the significances, even at a distance, through web interfaces.

So we propose that the advances of this paradigm consist in promoting the understanding of function, use and development of technological applications at the same time that it is constructed and used like a technological researching instrument and e-learning software. We had explained trough the transition of the stages of the logic of significances because we observed that the ontology scheme is result from them. This occurs during a process in which specialists of the technologies and other disciplines have collaborated to define, reformulate and posit an ontological scheme for solving knowledge problems.

This scheme is the result of a multidisciplinary analysis, incorporates the formulation or reformulation of fundamental concepts, propose a methodological process and definition of criteria for the significant analysis and interpretation of the representation of knowledge. All is explicit through the e-learning software while facilitating communication and knowledge exchange between the different systems and entities of the research group.

The knowledge construction processes described can be considered as a strategic KM because promotes, creates and transforms technology skills for use and design of e-learning methodologies and tools. At the same time the competitive capacity in academic organizations.

This paper reports an analytical and qualitative case study. Within the framework of institutional research conducted at UNAM, a collaboration agreement was established between two disciplinary projects [DP1] and [DP2] the first in technology and the other in social literature and politic. Both were integrated as a Multidisciplinary Researching-Teachinggroup that we will name MRT who proposed to observe the usefulness of semantic web to design and develop an e-learning software for social teaching.DP $1{ }^{1}$ propound researching and education as social

\footnotetext{
${ }^{1}$ The institutional project "PAPIME", (UNAM-PAPIME-304909) is derived from another more general one called "TIDI: Telematics for Research and Interdisciplinary Teaching," coordinated by the author of this article, whose specialty is characterized by multidisciplinary in the sphere of computer engineering and administration sciences. This project in turn involved the participation of an undergraduate student of information science.
} 
processes. So it researches the transformation of that and develops technological applications for their operative functional structure. DP1 coordinates and studies KM on multidisciplinary networks that are working in collaborative learning. The DP1 methodological process organizes the networks to transform and create their capacities for the informational analysis on social phenomena based on telematic technology. It developments technologic research instruments to study and understand these processes from complexity and KM perspectives. His central aim is evaluating and to propose models of technological appropriation in academic organizations [12].

The main objective for DP $2^{2}$ is to analyze the contribution of part of Mexican literature from the second half of the $20^{\text {th }}$ century, to understand left-wing politics; use academic precision and a solid empirical basis to analyze the overlapping of literature with the social sciences and enrich the epistemology of literary and cultural studies. The proposal for interdisciplinary collaboration arises from the need to remove the text from its limits by asking questions that had not been answered with the methods of literary analysis. The contribution of social disciplines to the project consists of proving the theoretical importance of studies on subjectivity to the comprehension of social issues; in other words, for the emotions and subjectivities to be an object of study of social sciences [13]. In the original methodological process, DP2 uses traditional research instrument on literature disciplinary. DP2 never had used telematic technology for the collaborative and multidisciplinary research and especially it never had used, designed or developed new technological instruments for e-learning.

MRT methodology studied the logic of significances as a research variable that had been observed to conduct the study empirically while the research group was designing a new technological instrument for social researching and e-learning so this process is considered a technologic appropriation process. Technological instrument designed is software based in semantic web. MRT analyzed the knowledge created at each of the three states described by Piagget on interdisciplinary and multidisciplinary fields simultaneously. The first field was studied while DP2 designed and developed the interdisciplinary ontology scheme for the Semantic web between literature and politics. The other field was studied while DP1 and DP2 designed and developed the software for e-learning that mean while multidisciplinary knowledge [literature, politic and technology] was created. (See Fig. 1).

We proposed the e-learning software is a representation of explicit knowledge through ICT at the same time it made possible to observe the ontological and concept scheme required to the design and implementation on the construction and use of the same platform. That is, the platform is our empirical research instrument

\footnotetext{
${ }^{2}$ The UNAM-PAPIIT-IN402207 project entitled "Literature and politics in Mexico. $20^{\text {th }}$ and $21^{\text {st }}$ Centuries," is coordinated by Drs. Gloria Patricia Cabrera López and Alba Teresa Estrada Castañón,whose specialties are literature (Mexican) and social sciences (political sociology), respectively. In addition to the coordinators, participants in this project included two doctoral students in Latin American studies, one person with an MA in art history and a student from the bachelor's degree course in information science.
}

\section{RESUlts}

The results of the analysis proved the usefulness of the semantic web paradigm for e=learning software because it gives capacity to encourage the construction of knowledge multidisciplinary linking the explicit representation in two ways:

For the construction of the Logic significances of an multidisciplinary researching-teaching group, this process is facilitated by the fact that it influences the understanding of the specific object of study and the subsequent processes of investigative analysis, interpretation and learning, due to the possibility of communicating the transmission of conceptual relations -inter-, intra- and trans-operatory- in its explicit representation in order to observe and interact in a multidisciplinary fashion, thereby favoring the consequent reformulation of meanings, in other words, of three crucial elements for DP2: the concepts, the analysis \&classification criteria and the interdisciplinary methodological processes, resulting from the researching into the literature and politics. That integrated social topics of e-learning software.

For the construction of the Logic of significances in the multidisciplinary relation, due to the fact that the process of design and construction of the ontological conceptual scheme of the semantic web that it forces to the researchers-teachers in both projects with various specialties to reformulate significances given the need for sharing and understanding the concepts, analysis \&classification criteria and multidisciplinary methodological processes to permit its explicit representation through a e-learning software. (See Fig. 2).

\begin{tabular}{|l|l|}
\hline \multicolumn{2}{|c|}{ a. Disciplinary Concepts } \\
\hline TT. Telematics technology & LP. Literature and Politic \\
\hline Technology & Literary analysis \\
\hline Technological appropriation & Poetic trends \\
\hline Use of technology & Concept \\
\hline Telematics & Category \\
\hline Telematic Platform & Common features \\
\hline Software engineering & Weighting \\
\hline Software & Characterization \\
\hline Commercial software & \\
\hline Systems programming & \\
\hline Classification criterion & \\
\hline
\end{tabular}

\begin{tabular}{|l|}
\hline \multicolumn{1}{|c|}{$\begin{array}{c}\text { b. Multidisciplinary Concepts } \\
\text { L } \cap \text { P } \cap \text { ICT }\end{array}$} \\
\hline Telematic Platform \\
\hline Web site \\
\hline Database administrator \\
\hline Management \\
\hline Consultation \\
\hline Key words \\
\hline Public access \\
\hline Documentary stock \\
\hline Typology \\
\hline Critical statement \\
\hline Catalogue of terms \\
\hline Abstract \\
\hline Textual quotes \\
\hline Construction of Logic of significances \\
\hline Evolution by Stages
\end{tabular}

Fig. 2. Semantic webconceptual scheme. 


\section{Tidi/LiteX, A Telematic Platform Prototype BASED ON THE SEMANTIC WEB THAT EXPLICITLY REPRESENTS THE LOGIC OF SIGNIFICANCES}

The preliminary $\mathrm{MR}$ result is a telematic platform prototype that consists of an automated system that it interconnects the disciplinary concepts of literature and politics. These are expressed in sources of documentary information classified in a multidisciplinary fashion and semantically linked through interdisciplinary classification criteria, which represent the significances of a common logic of analysis and interpretation. The representation of this logic is made explicit in the platform using the web sites.

On-line access to the websites is a consequence of various processes that automate the logical relations between those concepts, thereby explicitly showing the Logic of significances that contextualize research and permit the dissemination and spreading of research results through automated understanding on the Internet. In addition, the telematic platform prototype encourages the constant, permanent construction of knowledge during the automated evolution of the Logic of significances, due to the fact that it has a management system for the ongoing, dynamic updating of the concepts and classificatory criteria linking them through questionnaires on websites [12].

\section{CONCLUSION}

The research has shown that the usefulness of the paradigm of the semantic web lies in its capacity to objectify the linking process of explicit knowledge representations due it explains those processes as a functional structure of the logic of significances that it is essential to build knowledge on the $\mathrm{KM}$ in an academic organization. For that it has described the disciplinary problems for understanding the use and development of research instruments based on telematic technology in the social science sphere, immersed in the actual context which the technology has transformed the functioning forms of the scientific activities.

Particulary it has exposed the transcendence of multidisciplinary work between social, humanistic and technologic spheres for attending those problems on the KM strategy, specific to create competitive capacities in Mexican researchers at the UNAM. The preliminary results show an experience during the process of knowledge construction in the design and development of a research instruments based on technology telematic.

Despite that the personal availability, the disciplinary paradigms rooted and the personal functional contexts were not analysis variables it is important to highlight their incidence and importance because those are basic, fundamental and needed for to have an interaction between researchers, during on a mutidisciplinary or interdisciplinary researching. In some cases they can delay and complicate the building of the collective action schemes.

In general terms, this is interpreted as being the fact that nowadays, these factors are determined by the disciplinary specialization that internationally characterizes the academic institutions dedicated to education and research.

\section{REFERENCES}

[1] K. Wiig, "Knowledge management: An introduction and perspective," The Journal of Knowledge Management, vol. 1, no. 1, pp. 6-14, 1997.

[2] S. Shariq, "Knowledge management: An emerging discipline," Journal of the Academy of Management, vol. 1, no.1, pp. 75-82, 1997.

[3] R. McAdam and S. McCreedy, "A critical review or knowledge management models," The Leaming Organization, vol. 6, no. 3, 1999.

[4] J. Rowley, "Is higher education ready for knowledge management?" The International Journal of Educational Management, pp. 325-333, July 14, 2000.

[5] P. Carrillo, "Sociedad del conocimiento. academia, complejidad, administración y tecnología," UNAM-FCPyS-GEDISA, Distrito Federal, México, pp. 67-74, 2008.

[6] GDF-Gobierno del Distrito Federal. (2010). Becas ICyTDF y Becas Mujeres ICyTDF. Instituto de Ciencia y Tecnología del Distrito Federal, México. [Online]. pp. 1-26. Available: http://www.icyt.df.gob.mx/index.php?option=com_content $\& v i e w=a r t$ icle\&id=449\&Itemid $=183$

[7] M. Devedzic and V. Dvedzic. Imagine. (April 6, 2009). Using new web technologies in Demograph. Social Science Computer Review. [Online]. pp. 1-26. Available: http://ssc.sagepub.com hosted at http://online.sagepub.com

[8] T. B. Lee, J. Hendler, and O. Lassila. (May 2001). The semantic web. Scientific American Online. [Online]. pp. 35-43. Available: http://www.sciam.com

[9] W3C, World Wide Consortium. (2009). Vocabularies section. Online. [Online]. http://www.w3.org/standards/semanticweb/ontology

[10] J. Piaget and R. García, "Haciaunalógica de significaciones," Gedisa, España: Barcelona, pp. 13-118, 1999.

[11] P. G. Casanova, "Las nuevasciencias y lashumanidades. De la academia a la política," Antrophos-UNAM, España: Barcelona, 2004.

[12] P. Carrillo. (April 2010). Plataformatelemática TIDI-LITEX Telemáticapara la investigación y la docencia-LITEX. [Online]. Available: http://telematica.politicas.unam.mx/LITEX/Litex.php

[13] P. Carrillo, "Semantic web and logic of significances in the knowledge management of a social research group," in Proc. International Conference on Interactive Collaborative Learning ICL 2012, International Association of Online Engineeering (IAOE), Austria 2012 .

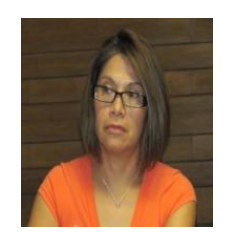

Carrillo Velázquez Lucía Patricia received $\mathrm{PhD}$.(M) of IAENG Number 2 on Monday 15th of April of 2013 in administration science (2008), and M.Cs in management organizations (2003) and E.C.S in computing engineer (1993) Universidad Nacional Autónoma de México. She is an holder academic at Centro de Investigaciones Interdisciplinarias en Ciencias y Humanidades (CEIICH), UNAM. México City. She was a head of the Computer Department of the same Institute. She is a University professor of graduate Program in Administration Science and in Latin American Studies. Researching Areas include Management of Knowledge, Intellectual Capital and Telematics Technology, Interdisiplinary Research-Teaching; Democratization of Knowledge; International Publicy Politics for access to the Internet; e-commerce, georeferencing Informatic Systems and digital publications.Carrillo, L. Patricia.PhD is Senior Member of IACSIT (No: 8034215/2012) and International Review Board of Informing Science Information Technology Education, InSITE 2012.Member Ship of Directorate General for the United Nations, at the preparatory process Forum on the preparatory process for the World Summit on Information Society. (WSIS), Member (No.502-1-1094.,2010).PhD. Carrillo L. Patricia is member the Registro Consejo Nacional de Ciencia y Tecnología (CONACYT) Acredited Assesors, for Registro CONACYT de Evaluadores Acreditados (RCEA) the Area 5. Social and Economícs, Member (No. 05-20020-2012). She is also a nacional researcher Level I for the Sistema Nacional de Investigadores (SNI) (CONACYT), 2011, and the Academic Committee of the Graduate Program In Management Sciences. 